\title{
COMMENTARY
}

\section{Is 'pre-eclampsia' simply a response to the side effects of a placental tachykinin?}

\author{
N M Page and P J Lowry \\ School of Animal and Microbial Sciences, The University of Reading, Whiteknights, Reading RG6 6AJ, UK \\ (Requests for offprints should be addressed to P J Lowry)
}

Pre-eclampsia $(\mathrm{PE})$ is a pregnancy-specific syndrome that is the principal cause of maternal morbidity and mortality, accounting for almost $15 \%$ of pregnancy-associated deaths (American College of Obstetricians and Gynecologists 1996). Hippocrates first described the condition when he wrote in one of his Aphorisms that 'convulsions take place from either repletion or depletion' (Salas 1999). Hippocrates had observed the sudden and unexpected appearance of maternal grand-mal seizures, which occur when PE progresses to eclampsia, the word being derived from the Greek for 'lightning'. It was believed for many centuries that PE was a seizure disorder unique to pregnancy, but during the last 200 years this view of the disease has changed drastically and we now know that it is not only a convulsive disorder. Several new findings have led to this change in opinion. At the turn of the last century, the new ability to measure blood pressure led to demonstration of the association of PE and hypertension (Cook \& Briggs 1903); hypertension was often found to precede the development of eclamptic seizures. Young (1927) described placental damage that led to pregnancy-induced toxaemia. Later, the involvement of the kidneys was also observed since women who had died from eclampsia also had a unique form of glomerular endotheliosis (Bell 1932). These findings persuaded many to view the syndrome as a hypertensive rather than a seizure disorder (American College of Obstetricians and Gynecologists 1996). This change in classification unfortunately led many researchers to devote attention to the cause of the hypertension, to the exclusion of other facets of the disease (Roberts \& Redman 1993). PE is now unanimously viewed as a multisystem disorder, as increases in blood pressure are rarely responsible for multi-organ dysfunction (Friedman et al. 1991).

What is the array of complications associated with PE? In its latest document, the National Institutes of Health (2000) define mild PE as including an increase in blood pressure to greater than $140 \mathrm{mmHg}$ systolic or $90 \mathrm{mmHg}$ diastolic in a woman normotensive before her 20th week of pregnancy. Proteinuria is also present with a urinary excretion of at least $0 \cdot 3 \mathrm{~g}$ protein in a $24 \mathrm{~h}$ specimen. Mild PE can develop directly into severe PE over a matter of days or weeks, this advancement being unpredictable in both its onset and its progression. There is a vast diversity of additional symptoms associated with this change (Patrick \& Roberts 1999). These can include cerebral oedema (Cunningham \& Twickler 2000), neurological manifestations (including headache, confusion, paralysis, coma, visual loss and seizures) (Royburt et al. 1991, Thomas 1998), liver capsule distension (Sheehan \& Lynch 1973), renal failure (Lindheimer \& Katz 1992), pulmonary oedema (Davison 1997), thrombocytopenia (Pritchard et al. 1987), coagulopathy (Barron et al. 1999), HELLP (haemolysis, elevated liver enzymes, and low platelet count) syndrome (Weinstein 1982) and nausea (Martin et al. 1999).

The primary cause of $\mathrm{PE}$ has been difficult to elucidate because its symptoms have always presented as a cluster of conditions. Several theories have been advocated and by far the most compelling evidence indicates that the placenta holds the key. The symptoms of PE disappear soon after birth or after pregnancy termination (Palma Gamiz 1998) when the placenta is no longer present. It is also apparent that the presence of a foetus is not necessary as some cases of hydatidiform mole, in which the uterus contains only disordered placental tissue, are complicated by the condition (Scott 1958). Finally, an utero-placental interaction is not required, as abdominal pregnancies can still encounter complications (Shembrey \& Noble 1995). However, as PE affects only $5-10 \%$ of first pregnancies the presence of a placenta cannot be the sole cause. What then is different in the placentae of women prone to develop PE? Page (1939) first noted that placentae from these women appeared to be poorly perfused and today we know that a consistent feature associated with this poor perfusion is the defective trophoblast invasion of the myometrial portion of the spiral arteries (Pijnenborg et al. 1980, 1981). In normal pregnancy, trophoblast invasion of the spiral arteries renders them dilated, flaccid and unresponsive to vasoconstrictive agents (Brosens et al. 
1970), but if a defective invasion occurs the spiral arteries retain their musculo-elastic properties and responsiveness to vasoactive substances (Lim et al. 1997). This is thought to lead to placental ischaemia and eventually to the observed endothelial dysfunction (Roberts et al. 1989) with, finally, the clinical syndrome of PE. Many groups have hypothesised that the ischaemic placenta releases an unknown factor(s) into the maternal circulation which then causes the multi-system complications (Higgins \& Brennecke 1998, Roberts 1998, Taylor et al. 1998, Van Wijk et al. 2000). Roberts (1998) predicted that any candidate molecule(s) would not be unique but rather a known molecule(s) that is present in excessive amounts. We believe that any factor capable of causing PE must be able to inflict its effects not only at the utero-placental boundary but also at peripheral sites if it is to cause the diversity of symptoms seen in different patients.

McGuinness (1963) first presented evidence that the PE factor may be a neuropeptide. An intact frog (skin) bioassay was used to demonstrate that there were grossly increased concentrations of 'melanocyte-stimulating hormone (MSH) activity' in extracts of plasma taken from women suffering from PE. Attempts to confirm this observation using an isolated frog skin system in vitro (Chadwick \& Lowry 1970) were unsuccessful (R E Silman \& P J Lowry, unpublished observations) and we concluded that this 'PE factor' was activating the intact frog's own neuroendocrine MSH system at a higher level. One potential candidate was corticotrophin-releasing factor (CRF). In its normal hypothalamic role CRF stimulates the release of adrenocorticotrophin/MSH peptides from the pituitary gland; however, it was also found to be secreted by the placenta into the maternal blood in nanomolar concentrations during normal pregnancy. These levels were found to be some 3-fold higher in pregnancy-induced hypertension (PIH) (Campbell et al. 1987). However, the presence in blood of a CRF-binding protein (Behan et al. 1989, Linton et al. 1993) that was effective in neutralising the activity of the placental CRF suggested it did not contribute to the PIH. There was also a discrepancy in the levels of CRF observed (3-fold) and the 'MSH activity' (100-fold) seen by McGuinness (1963). These observations led us to continue our search for the identity of the 'PE neuropeptide'.

We extended our approach by using a range of recently developed molecular biological and bio-informatic tools. We adopted two main strategies: (i) the development of a profile of placental gene expression during the first trimester of pregnancy (Page et al. 2000a) and (ii) a systematic bio-informatic database search to identify and reconstruct the full-length cDNA of expressed sequence tags (ESTs) previously uncharacterised in the human placenta. Our searches have led to the creation of a placental database containing more than 2000 known genes, ESTs and uncharacterised genes. From this pool we

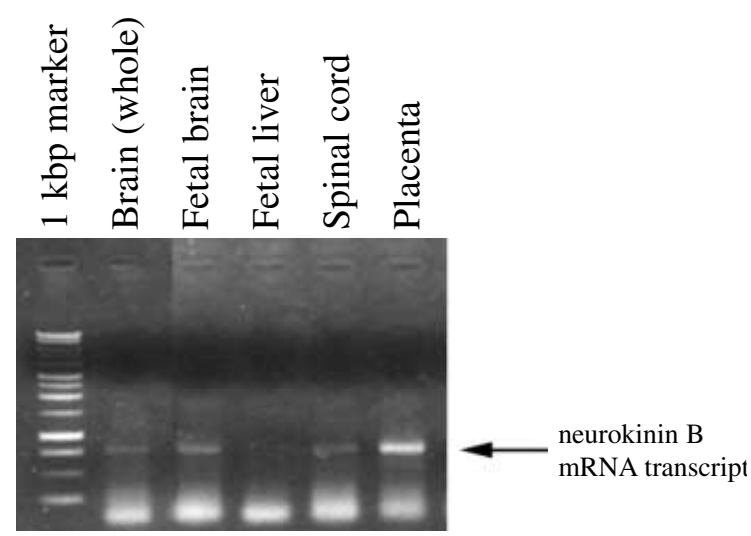

Figure 1 Semi-quantitative RT-PCR of the full-length NKB mRNA transcript. NKB mRNA transcripts were amplified from human whole brain, foetal brain, foetal liver, spinal cord and placenta.

identified a number of ESTs showing a high homology with the bovine neurokinin $\mathrm{B}(\mathrm{NKB})$ precursor (Kotani et al. 1986). We were able to clone the full-length human NKB gene from the placenta and locate its expression by in situ hybridisation to the outer syncytiotrophoblasts. These cells are responsible for the secretion of numerous pregnancy-associated polypeptides into the maternal circulation, most notably chorionic gonadotrophin. Using an RIA, NKB concentrations in the plasma of 30 normotensive pregnant women were found to be low or not detected throughout pregnancy, although a proportion exhibited a slight increase at term (less than $1 \mathrm{nmol} / \mathrm{l}$ ). Four normotensive women between weeks 9 and 14 also had concentrations equivalent to the highest at term. All the eight PE women examined in their third trimester were found to have considerably higher levels of NKB (between 1 and $7 \mathrm{nmol} / \mathrm{l}$ ). The i.v. infusion of high concentrations of $\mathrm{NKB}$ into female unrestrained rats caused a significant, transient, increase in arterial pressure and a gain in uterine wet weight of $37 \%$ (Page et al. 2000b). In future, it will be of interest to inject NKB into frogs to confirm that it can activate the 'MSH' axis.

The discovery of NKB expression in the placenta and the maternal circulation raises some interesting questions with regard to its role both in normal reproductive physiology and in the pathology of PE. We are the first to demonstrate that this peptide is expressed in the periphery. An extensive distribution search for NKB by Moussaoui et al. (1992), using specific RIAs, in the rat, did not reveal NKB in any peripheral tissue examined. Their search, however, did not include the placenta, where we have since found NKB mRNA expression levels in humans to be even greater than in the brain or spinal cord (Fig. 1). We have also examined the expression of the substance $\mathrm{P}$ (SP)/neurokinin A (NKA) gene mRNA transcript(s) representing the two other mammalian tachykinins. We found the transcript to be expressed in most tissues 
analysed including regions of the central nervous system, although interestingly we failed to detect its expression in the human placenta (results not shown). A recent report by Patacchini et al. (2000) states that the physiological significance of the NKB-preferred receptor, NK3, in the peripheral nervous system is uncertain as NKB is either not expressed in peripheral tissues or is present in extremely low amounts compared with those of SP and NKA. Now, perhaps, the observation of NK3 receptors in the circulatory system no longer remains an enigma. The activation of NK3 receptors in the vascular system has been reported to cause the contraction of the hepatic portal vein (Mastrangelo et al. 1987), venoconstriction of the mesenteric beds (D'Orleans-Juste et al. 1991) and increased heart rate (Thompson et al. 1998). It is perfectly feasible to suggest now that during pregnancy the secretion of NKB from the placenta activates these receptors and could be responsible for some of the haemodynamic adaptations observed during gestation. The basic mechanisms underlying haemodynamic alterations in pregnancy are virtually unknown (Thornburg et al. 2000). Normally both maternal blood volume and red cell mass increase gradually throughout gestation. Stroke volume and heart rate increase gradually, along with venous compliance and venous blood volume, whereas systolic and diastolic blood pressures decrease (Thornburg et al. 2000). These changes coincide with a redistribution of blood flow from some maternal organs to the uterus and placenta (Buelke-Sam et al. 1982, Dowell \& Kauer 1997). Evidence from the infusion of high doses of NKB into female rats would indicate that NKB might be involved in some of these haemodynamic events. Our data suggest that NKB could be causing vascular changes, not only by increasing maternal blood pressure, but also by shunting blood from organs, including the liver and mesenteric beds, to the uterus and placenta. We cannot yet determine the precise mechanism of action but we speculate that, when the uterus and placenta need a greater supply of blood, the placenta begins to secrete NKB. This secretion into the circulation may activate NK3 receptors on the venous side of the maternal system, causing the blood pressure to increase by the contraction of the large veins of the mesenteric beds and the hepatic portal vein. This, in turn, reduces the blood flow to the liver allowing an increase in blood flow to the uterus. This would represent a novel mechanism whereby increases in maternal blood pressure occur from the venous side of the system. This is in contrast to the usual manner of arterial blood pressure increases that are associated with essential hypertension in males and non-pregnant females. We believe that we are the first to propose this theory, although not the first to make such an observation. Two groups (Stainer et al. 1986, Sakai et al. 1994) have observed that venous abnormalities involving decreased venous distensibility might contribute to the impaired control of haemodynamics found in PE. Such a mechanism would not need to be switched on permanently; indeed, most normotensive pregnancies showed low or not detected levels of NKB. Nevertheless, it is apparent that the activation of NK3 receptors by NKB could reduce the blood flow through the liver, satisfying the needs of the uterus and placenta; indeed, in rats (Buelke-Sam et al. 1982) and rabbits (Nuwayhid 1979) cardiac output to the liver is consistently reduced throughout gestation. We were particularly interested to note that four women with normotensive pregnancies between weeks 9 and 14 had concentrations of NKB equivalent to the highest values that we found at term. We therefore speculate that an increase in NKB expression occurs at a time when intervillous blood flow to the placenta increases at around 10 to 12 weeks - a period that represents a change in the placental environment from a relative hypoxia to an increase in oxygen tension (Jaffe et al. 1997). Low oxygen tension appears to prevent trophoblast differentiation towards an invasive phenotype (Genbacev et al. 1996) and optimal placental perfusion requires the controlled invasion of the trophoblast cells deep into the myometrial spiral arteries; the narrow walls of the spiral arteries are replaced with the trophoblasts, rendering them flaccid and distended, and resulting in an increase of blood flow to the placenta. At this critical period, a transient surge in $\mathrm{NKB}$ secretion may be required to improve perfusion or increase vascularisation in the newly established placental bed.

What is the role of NKB in the pathogenesis of PE? Two main stages seem to occur in the development of PE. We believe that NKB is the factor that links these two stages. The first stage appears to involve the defective trophoblastic invasion of the spiral arteries, the placenta becomes poorly perfused and ischaemia develops. The suggested maternal risk factors have been extensively reviewed; they include immune maladaptation (Dekker \& Sibai 1999), genetic predisposition (Broughton Pipkin 1999), underlying diseases (Dekker 1999) and environmental factors (Neela \& Raman 1993). We propose that, if the defective trophoblast invasion does not rectify itself after the 10th to 12 th weeks of pregnancy, the placenta will start to secrete NKB into the maternal circulation in ever-increasing amounts; in most normal pregnancies, small surges of NKB may be observed around this period of correction. The extremely high levels of NKB detected in the plasma in third trimester pre-eclamptics identify a group of women in whom the invasion of the trophoblasts was never completed satisfactorily. In this case, the secretion of NKB could begin as early as the 10th week of pregnancy. NKB is, conceivably, the key factor involved in initiation of the second stage of the disease, in which the clinical syndrome of PE develops, as NKB alone could account for many of the diverse symptoms. The stimulation of NK3 receptors could lead to constriction and contraction of the mesenteric and hepatic portal veins, with an increase in blood pressure and potential damage to 

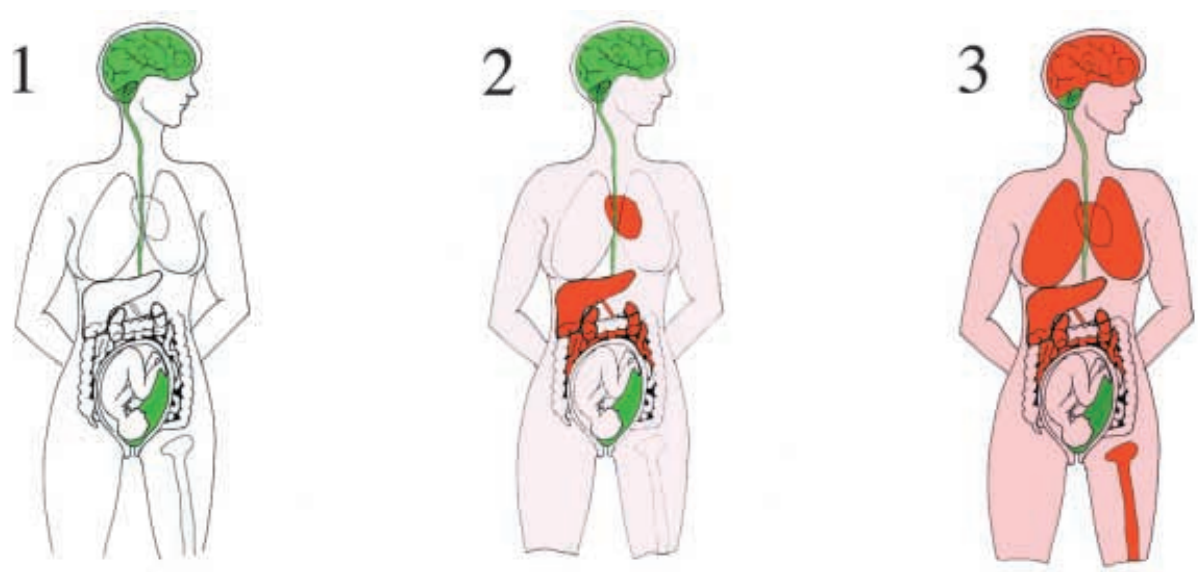

Figure 2 Our NKB theory behind the multiple symptoms of PE. In normal pregnancy NKB is found in the brain, spinal cord and placenta (Patient 1). If trophoblast invasion is incomplete, the placenta starts releasing NKB into the maternal circulation. This causes contraction of the mesenteric and the hepatic portal vein and increases the heart rate (Patient 2). If this cannot rectify the problem then the placenta secretes greater amounts of NKB, leading to the host of life-threatening symptoms associated with the clinical manifestation of PE (Patient 3). Drawing by Virginia France.

the kidneys and liver (Fig. 2); furthermore the reduction in blood flow to the liver would result in an accumulation of toxic metabolic products, such as lipid peroxides, which may contribute to endothelial cell damage and dysfunction. In the more severe cases, the concentrations of NKB may be sufficient to stimulate peripheral NK1 receptors; for example, activation of receptors found on platelets (Gecse et al. 1996) and neutrophils (Perianin et al. 1989, Perretti et al. 1993) may contribute to the complications of PE. High circulating NKB concentrations could also be responsible for the cerebral complications of $\mathrm{PE}$; high intravascular concentrations of SP have been shown to dilate cerebral blood vessels via NK1 receptors (Jansen et al. 1991, Kobari et al. 1996) located to the endothelium (Shimizu et al. 1999). Many other potential markers for PE have been reported (Higgins \& Brennecke 1998, Roberts 1998, Taylor et al. 1998, Wang \& Trudinger 1998), although no evidence exists to suggest that any of these are the direct cause of PE. For example, decreased levels of prostacyclin (Bussolino et al. 1980), increased levels of thromboxane (Mills et al. 1999) and variably reported levels of nitric oxide (Buhimschi et al. 1998) could all be secondary to endothelial dysfunction. Low levels of nitric oxide synthetase (Guo et al. 1999) and protein C resistance (Leiden V mutation; Spina et al. 2000) often appear secondary to genetic predisposition. The increased levels of circulating vascular cell adhesion molecule-1 (Lyall et al. 1994) and the variably reported levels of intercellular cell adhesion molecule-1 and E-selectin (Krauss et al. 1997, Lyall et al. 1994) are likely to represent molecules shed as a result of neutrophil-endothelial interactions.

What of the prospects of developing a diagnostic test? The availability of such a diagnostic tool would be useful for both diagnosis and basic research, but at the present time no such test exists. A selective marker would have to be one that uniquely predicts and/or specifically accompanies the clinical manifestations and is absent from other hypertensive disorders. Preliminary evidence suggests that NKB may fulfil these criteria, as it was present in high concentrations in the plasma of the eight preeclamptic women examined (1-7 nmol/l). NKB plasma levels were low or not detected in most normotensive pregnancies studied and also in those of males and nonpregnant females (Page et al. 2000b). We also screened males and non-pregnant females who were receiving medication for essential hypertension, and NKB was again not detected. Much work still needs to be carried out as present assays are laborious and imprecise; therefore the first aim is to design a specific immunoassay that can be performed routinely in the clinical setting. In addition, large longitudinal studies are required to determine the diagnostic value of $\mathrm{NKB}$ at various stages of pregnancy. PE diagnosis is often complicated by other disorders such as the development of gestational hypertension and ensuing essential hypertension (Brown \& de Swiet 1999); this leads to problems, not only in predicting disease outcome and epidemiology, but also in the selection of cases for scientific study. At the present time, over-diagnosis remains the safest strategy for patients.

Once a reliable diagnosis of PE is available, what treatments can be offered? The availability of potent and selective antagonists for the NK receptors may allow alternative and potentially more effective treatment strategies. Administration of NK3 receptor antagonists could alleviate the effects of high circulating levels of NKB in the plasma of mothers suffering from 
hypertension by reducing the vasoconstrictive effects of NKB. Careful management of the blood pressure, however, will also be important, as reducing it too much may not only compromise the welfare of the foetus, but may even lead to higher concentrations of the peptide through compensatory secretion of NKB. In severe cases, high concentrations of NKB could activate NK1 receptors, leading to the other complications associated with PE. Here, a combination of NK3 and NK1 receptor antagonists or a broad-spectrum NK receptor antagonist may be the treatment of choice. To date, many non-specific treatments have been offered to deal with the two main complications of PE hypertension and seizures. In the first instance, a range of adrenergic-blocking drugs ( $\beta$-blockers and $\alpha-\beta$ blockers) (Magee et al. 1999), calcium antagonists (Magee et al. 1996), diuretic agents (Collins et al. 1985) and angiotensin-converting enzyme inhibitors (Hanssens et al. 1991) have been used. Problems encountered include those associated with the use of prazosin which reduces arterial pressure by dilating both arterial resistance and venous capacitance vessels, thus reducing the blood supply to the uterus and causing a higher incidence of intrauterine deaths (Hall et al. 2000). In the case of seizure management, magnesium sulphate (Chien et al. 1996) and phenytoin (Lucas \& Jordan 1997) have been shown to limit the frequency of the attacks. Also, a number of very general treatments have been suggested for the prevention of PE including aspirin (Christian 1999), calcium supplementation (Ritchie \& King 2000) and other dietary supplements (such as vitamins C and E) (Chappell et al. 1999). As the direct cause of PE remains undefined, these general treatments can only help to relieve the symptoms whilst the underlying factors triggering the initiation of the disease process remain uncontrolled. NKB antagonists, however, may be able to target not only the hypertension and the seizures, but also other symptoms caused by the direct activation of NK receptors. Nevertheless, the development of an NK antagonist would have to follow strict guidelines and include large multi-centre randomised trials to determine the extent of teratogenicity, foetal growth retardation, miscarriage and any other detrimental physiological effects on both the foetus and mother. However, treatment may be necessary only during the third trimester - a time when many of these effects are receding. With the benefit of an early warning test, the need for very early induction of labour and elective caesarean section may be significantly reduced.

Zweifel (1916) first described PE as 'a disease of theories'. Higgins \& Brennecke (1998) re-stated that 'pre-eclampsia ... was still a disease of theories'. Will the NKB theory be able to supersede previous hypotheses and if it becomes a reality will it offer the potential for the first early predictive test and targeted treatment for this life-threatening disease?

\section{References}

American College of Obstetricians and Gynecologist 1996 Hypertension in pregnancy. American College of Obstetricians and Gynecologists Technical Bulletins 219 1-8.

Barron WM, Heckerling P, Hibbard JU \& Fisher S 1999 Reducing unnecessary coagulation testing in hypertensive disorders of pregnancy. Obstetrics and Gynecology 94 364-370.

Behan DP, Linton EA \& Lowry PJ 1989 Isolation of the human plasma corticotrophin-releasing factor-binding protein. Journal of Endocrinology 122 23-31.

Bell ET 1932 Renal lesions in the toxemias of pregnancy. American Journal of Pathology 8 1-42.

Brosens IA, Robertson WB \& Dixon HG 1970 The role of the spiral arteries in the pathogenesis of preeclampsia. Journal of Pathology 1066.

Broughton Pipkin F 1999 What is the place of genetics in the pathogenesis of pre-eclampsia? Biology of the Neonate 76 325-330.

Brown MA \& de Swiet M 1999 Classification of hypertension in pregnancy. Baillieres Clinical Obstetrics and Gynaecology 13 27-39.

Buelke-Sam J, Nelson CJ, Byrd RA \& Holson JF 1982 Blood flow during pregnancy in the rat: I. Flow patterns to maternal organs. Teratology 26 269-277.

Buhimschi IA, Saade GR, Chwalisz K \& Garfield RE 1998 The nitric oxide pathway in pre-eclampsia: pathophysiological implications. Human Reproduction Update 4 25-42.

Bussolino F, Benedetto C, Massobrio M \& Camussi G 1980 Maternal vascular prostacyclin activity in pre-eclampsia. Lancet ii 702-702.

Campbell EA, Linton EA, Wolfe CD, Scraggs PR, Jones MT \& Lowry PJ 1987 Plasma corticotrophin-releasing hormone concentrations during pregnancy and parturition. Journal of Clinical Endocrinology and Metabolism 64 1054-1059.

Chadwick A \& Lowry PJ 1970 In vitro assay of MSH using skin from the frog Hyla arbore. General and Comparative Endocrinology 15 493-495.

Chappell LC, Seed PT, Briley AL, Kelly FJ, Lee R, Hunt BJ, Parmar K, Bewley SJ, Shennan AH, Steer PJ \& Poston L 1999 Effect of antioxidants on the occurrence of pre-eclampsia in women at increased risk: a randomised trial. Lancet 354 810-816.

Chien PF, Khan KS \& Arnott N 1996 Magnesium sulphate in the treatment of eclampsia and pre-eclampsia: an overview of the evidence from randomised trials. British Journal of Obstetrics and Gynaecology 103 1085-1091.

Christian R 1999 Low-dose aspirin therapy in the treatment of preeclampsia. Nurse Practitioner 24 138-139.

Collins R, Yusuf S \& Peto R 1985 Overview of randomised trials of diuretics in pregnancy. British Medical Journal (Clinical Research Edition) 290 17-23.

Cook HW \& Briggs JB 1903 Clinical observations on blood pressure. Johns Hopkins Hospital Reports 11 452-534.

Cunningham FG \& Twickler D 2000 Cerebral edema complicating eclampsia. American Journal of Obstetrics and Gynecology 182 94-100.

Davison JM 1997 Edema in pregnancy. Kidney International Supplement 59 S90-S96.

Dekker GA 1999 Risk factors for preeclampsia. Clinical Obstetrics and Gynecology 42 422-435.

Dekker GA \& Sibai BM 1999 The immunology of preeclampsia. Seminars in Perinatology 23 24-33.

D'Orleans-Juste P, Claing A, Telemaque S, Warner TD \& Regoli D 1991 Neurokinins produce selective venoconstriction via NK-3 receptors in the rat mesenteric vascular bed. European Journal of Pharmacology 204 329-334.

Dowell RT \& Kauer CD 1997 Maternal hemodynamics and uteroplacental blood flow throughout gestation in conscious rats. Methods and Findings in Experimental and Clinical Pharmacology 19 613-625.

Friedman SA, Taylor RN \& Roberts JM 1991 Pathophysiology of preeclampsia. Clinical Perinatology 18 661-682. 
Gecse A, Kis B, Mezei Z \& Telegdy G 1996 The effect of bradykinin and substance $\mathrm{P}$ on the arachidonate cascade of platelets. Immunopharmacology 33 167-170.

Genbacev O, Joslin R, Damsky CH, Polliotti BM \& Fisher SJ 1996 Hypoxia alters early gestation human cytotrophoblast differentiation/ invasion in vitro and models the placental defects that occur in preeclampsia. Journal of Clinical Investigation 97 540-550.

Guo G, Lade JA, Wilton AN, Moses EK, Grehan M, Fu Y, Qiu H, Cooper DW \& Brennecke SP 1999 Genetic susceptibility to pre-eclampsia and chromosome 7q36. Human Genetics 105 641-647.

Hall DR, Odendaal HJ, Steyn DW \& Smith M 2000 Nifedipine or prazosin as a second agent to control early severe hypertension in pregnancy: a randomised controlled trial. British Journal of Obstetrics and Gynaecology 107 759-765.

Hanssens M, Keirse MJ, Vankelecom F \& Van Assche FA 1991 Fetal and neonatal effects of treatment with angiotensin-converting enzyme inhibitors in pregnancy. Obstetrics and Gynecology 78 128-135.

Higgins JR \& Brennecke SP 1998 Pre-eclampsia - still a disease of theories? Current Opinions in Obstetrics and Gynecology 10 129-133.

Jaffe R, Jauniaux E \& Hustin J 1997 Maternal circulation in the first-trimester human placenta - myth or reality? American Journal of Obstetrics and Gynecology 176 695-705.

Jansen I, Alafaci C, McCulloch J, Uddman R \& Edvinsson L 1991 Tachykinins (substance $\mathrm{P}$, neurokinin A, neuropeptide $\mathrm{K}$, and neurokinin $\mathrm{B}$ ) in the cerebral circulation: vasomotor responses in vitro and in situ. Journal of Cerebral Blood Flow and Metabolism 11 $567-575$.

Kobari M, Tomita M, Tanahashi N, Yokoyama M, Takao M \& Fukuuchi Y 1996 Intravascular substance P dilates cerebral parenchymal vessels through a specific tachykinin NK1 receptor in cats. European Journal of Pharmacology 317 269-274.

Kotani H, Hoshimaru M, Nawa H \& Nakanishi S 1986 Structure and gene organization of bovine neuromedin K precursor. PNAS $\mathbf{8 3}$ 7074-7078.

Krauss T, Kuhn W, Lakoma C \& Augustin HG 1997 Circulating endothelial cell adhesion molecules as diagnostic markers for the early identification of pregnant women at risk for development of preeclampsia. American Journal of Obstetrics and Gynecology 177 443-449.

Lim KH, Zhou Y, Janatpour M, McMaster M, Bass K, Chun SH \& Fisher SJ 1997 Human cytotrophoblast differentiation/invasion is abnormal in pre-eclampsia. American Journal of Pathology 151 1809-1818.

Lindheimer MB \& Katz AI 1992 Renal physiology and disease in pregnancy. In The Kidney: Physiology and Pathophysiology, edn 2, pp 3371-3431. Eds DW Seldin \& G Giebisch. New York: Raven Press.

Linton EA, Perkins AV, Woods RJ, Eben F, Wolfe CD, Behan DP, Potter E, Vale WW \& Lowry PJ 1993 Corticotropin releasing hormone-binding protein (CRH-BP): plasma levels decrease during the third trimester of normal human pregnancy. Journal of Clinical Endocrinology and Metabolism 76 260-262.

Lucas LS \& Jordan ET 1997 Phenytoin as an alternative treatment for preeclampsia. Journal of Obstetric, Gynecologic, and Neonatal Nursing $26263-269$.

Lyall F, Greer IA, Boswell F, Macara LM, Walker JJ \& Kingdom JC 1994 The cell adhesion molecule, VCAM-1, is selectively elevated in serum in pre-eclampsia: does this indicate the mechanism of leucocyte activation? British Journal of Obstetrics and Gynaecology 101 485-487.

McGuinness BW 1963 Melanocyte-stimulating hormone: a clinical and laboratory study. Annals of the New York Academy of Sciences $\mathbf{1 0 0}$ 640-657.

Magee LA, Schick B, Donnenfeld AE, Sage SR, Conover B, Cook L, McElhatton PR, Schmidt MA \& Koren G 1996 The safety of calcium channel blockers in human pregnancy: a prospective, multicenter cohort study. American Journal of Obstetrics and Gynecology 174 823-828.

Magee LA, Ornstein MP \& Von Dadelszen P 1999 Fortnightly review; management of hypertension in pregnancy. British Medical Journal 318 1332-1336.

Martin JN, Rinehart BK, May WL, Magann EF, Terrone DA \& Blake PG 1999 The spectrum of severe preeclampsia: comparative analysis by HELLP (hemolysis, elevated liver enzyme levels, and low platelet count) syndrome classification. American Journal of Obstetrics and Gynecology 180 1373-1384.

Mastrangelo D, Mathison R, Huggel HJ, Dion S, D’Orleans-Juste P, Rhaleb NE, Drapeau G, Rovero P \& Regoli D 1987 The rat isolated portal vein: a preparation sensitive to neurokinins, particularly neurokinin B. European Journal of Pharmacology 134 321-326.

Mills JL, DerSimonian R, Raymond E, Morrow JD, Roberts LJ, Clemens JD, Hauth JC, Catalano P, Sibai B, Curet LB \& Levine RJ 1999 Prostacyclin and thromboxane changes predating clinical onset of preeclampsia: a multicenter prospective study. Journal of the American Medical Association 282 356-362.

Moussaoui SM, Le Prado N, Bonici B, Faucher DC, Cuine F, Laduron PM \& Garret C 1992 Distribution of neurokinin B in rat spinal cord and peripheral tissues: comparison with neurokinin $\mathrm{A}$ and substance $\mathrm{P}$ and effects of neonatal capsaican treatment. Neuroscience 48 969-978.

National Institutes of Health 2000 Working Group Report On High Blood Pressure in Pregnancy. NIH publication No. 00-3029, July.

Neela J \& Raman L 1993 Seasonal trends in the occurrence of eclampsia. National Medical Journal of India 6 17-18.

Nuwayhid B 1979 Hemodynamic changes during pregnancy in the rabbit. American Journal of Obstetrics and Gynecology 135 590-596.

Page EW 1939 The relation between hydatid moles, relative ischemia of the gravid uterus, and the placental origin of eclampsia. American Journal of Obstetrics and Gynecology 37 291-293.

Page N, Butlin D, Manyonda I \& Lowry P 2000a The development of a genetic profile of placental gene expression during the first trimester of pregnancy: a potential tool for identifying novel secreted markers. Fetal Diagnosis and Therapy 15 237-245.

Page NM, Woods RJ, Gardiner SM, Lomthaisong K, Gladwell RT, Butlin DJ, Manyonda IT \& Lowry PJ $2000 b$ Excessive secretion of neurokinin $\mathrm{B}$ during the third trimester causes pre-eclampsia. Nature 405 797-800.

Palma Gamiz JL 1998 Arterial hypertension and pregnancy: diagnostic criteria and therapeutic approach. Revista Espanola de Cardiologica $\mathbf{5 1}$ (Suppl) 50-58.

Patacchini R, Maggi CA \& Holzer P 2000 Tachykinin autoreceptors in the gut. Trends in Pharmacological Sciences 21166.

Patrick T \& Roberts JM 1999 Current concepts in preeclampsia. MCN: American Journal of Maternal Child Nursing 24 193-200.

Perianin A, Snyderman R \& Malfroy B 1989 Substance P primes human neutrophil activation: a mechanism for neurological regulation of inflammation. Biochemical and Biophysical Research Communications 161 520-524.

Perretti M, Ahluwalia A, Flower RJ \& Manzini S 1993 Endogenous tachykinins play a role in IL-1-induced neutrophil accumulation: involvement of NK-1 receptors. Immunology 80 73-77.

Pijnenborg R, Dixon G, Robertson WB \& Brosens I 1980 Trophoblastic invasion of human decidua from 8 to 18 weeks of pregnancy. Placenta 1 3-19.

Pijnenborg R, Bland JM, Robertson WB, Dixon G \& Brosens I 1981 The pattern of interstitial trophoblastic invasion of the myometrium in early human pregnancy. Placenta 2 303-316.

Pritchard JA, Cunningham FG, Pritchard SA \& Mason RA 1987 How often does maternal preeclampsia-eclampsia incite thrombocytopenia in the fetus? Obstetrics and Gynecology 69 292-295. 
Ritchie LD \& King JC 2000 Dietary calcium and pregnancy-induced hypertension: is there a relation? American Journal of Clinical Nutrition 71 (Suppl) 1371S-1374S.

Roberts JM 1998 Endothelial dysfunction in preeclampsia. Seminars in Reproductive Endocrinology 16 5-15.

Roberts J \& Redman C 1993 Pre-eclampsia: more than pregnancy induced hypertension. Lancet 341 1447-1451.

Roberts JM, Taylor RN, Musci TJ, Rodgers GM, Hubel CA \& McLaughin MK 1989 Preeclampsia: an endothelial cell disorder. American Journal of Obstetrics and Gynecology 161 1200-1204.

Royburt M, Seidman DS, Serr DM \& Mashiach S 1991 Neurologic involvement in hypertensive disease of pregnancy. Obstetrical and Gynecological Survey 46 656-664.

Sakai K, Imaizumi T, Maeda H, Nagata H, Tsukimori K, Takeshita A \& Nakano H 1994 Venous distensibility during pregnancy. Comparisons between normal pregnancy and preeclampsia. Hypertension 24 461-466.

Salas SP 1999 What causes pre-eclampsia? Baillieres Clinical Obstetrics and Gynaecology 13 41-57.

Scott JS 1958 Pregnancy toxaemia associated with hydrops foetalis, hydatidiform mole and hydramnios. Journal of Obstetrics and Gynaecology of the British Empire 65 689-701.

Sheehan HL \& Lynch JB 1973 Pathology of Toxaemia of Pregnancy. Eds Williams \& Wilkins. London: Churchill Livingstone.

Shembrey MA \& Noble AD 1995 An instructive case of abdominal pregnancy. Australian and New Zealand Journal of Obstetrics and Gynecology 35 220-221.

Shimizu T, Koto A, Suzuki N, Morita Y, Takao M, Otomo S \& Fukuuchi Y 1999 Occurrence and distribution of substance P receptors in the cerebral blood vessels of the rat. Brain Research $\mathbf{8 3 0}$ 372-378.

Spina V, Aleandri V \& Morini F 2000 The impact of the factor V Leiden mutation on pregnancy. Human Reproduction Update 6 301-306.
Stainer K, Morrison R, Pickles C \& Cowley AJ 1986 Abnormalities of peripheral venous tone in women with pregnancy-induced hypertension. Clinical Science 70 155-157.

Taylor RN, de Groot CJM, Cho YK \& Lim K-H 1998 Circulating factors as markers and mediators of endothelial cell dysfunction in preeclampsia. Seminars in Reproductive Endocrinology 16 17-31.

Thomas SV 1998 Neurological aspects of eclampsia. Journal of Neurological Science 1565 37-43.

Thompson GW, Hoover DB, Ardell JL \& Armour JA 1998 Canine intrinsic cardiac neurons involved in cardiac regulation possess NK1, NK2 and NK3 receptors. American Journal of Physiology: Regulatory Integrative and Comparative Physiology 44 1683-1689.

Thornburg KL, Jacobson SL, Giraud GD \& Morton MJ 2000 Hemodynamic changes in pregnancy. Seminars in Perinatology 24 $11-14$.

Van Wijk MJ, Kublickiene K, Boer K \& Van Bavel E 2000 Vascular function in preeclampsia. Cardiovascular Research 47 38-48.

Wang J \& Trudinger B 1998 Endothelial cell dysfunction in preeclampsia. Journal of Nephrology 11 53-56.

Weinstein L 1982 Syndrome of hemolysis, elevated liver enzymes, and low platelet count: a severe consequence of hypertension in pregnancy. American Journal of Obstetrics and Gynecology 142 159-167.

Young J 1927 Recurrent pregnancy toxaemia and its relation to placental damage. Transactions of the Edinburgh Obstetrics Society 47 61-76.

Zweifel P 1916 Eklampsie. In Handbuch der Geburtshilfe, vol 2, pp 672-723. Ed. A Dederlein. Wiesbade: Bergmann.

Revised manuscript received 8 August 2000 Accepted 22 September 2000 